\title{
The Study of Placental Vascularization Using Type AGO II Plastic Substances
}

\author{
CATALIN DUMITRU ${ }^{1 \#, ~ I Z A B E L L A ~ P E T R E ~}{ }^{1 \#,}$ MARIUS CRAINA ${ }^{1}$, LAVINIA CRISTINA MOLERIU", NICOLAE SUCIU4*, \\ CAROLINA GOBJILA ${ }^{1}$, ELENA POP 5 , ALINA SISU ${ }^{5}$, DANIELA RADU6*, ROXANA OANCEA ${ }^{7}$ \\ IVictor Babes University of Medicine and Pharmacy, Department XII, Discipline of Obstetrics and Gynecology, 2 Eftimie Murgu \\ Sq., 300041, Timisoara, Romania \\ 2 Victor Babes University of Medicine and Pharmacy, Department of Functional Sciences, Medical Informatics and Biostatistics \\ Discipline, 2 Eftimie Murgu Sq., 300041, Timisoara, Romania \\ ${ }^{4}$ Carol Davila University of Medicine and Pharmacy, Department of Obstetrics and Gynecology, Alfred Rusescu Institute for \\ Mother and Child Care, 120 Lacul Tei, 020395, Bucharest, Romania \\ ${ }^{5}$ Victor Babes University of Medicine and Pharmacy, Faculty of Medicine Anatomy and Embriology Department, 2 Eftimie Murgu \\ Sq., 300041, Timisoara, Romania \\ Victor Babes University of Medicine and Pharmacy Surgery Department, 2 Eftimie Murgu Sq., 300041,Timisoara, Romania \\ TVictor Babes University of Medicine and Pharmacy, Faculty of Dental Medicine, Department I, 14A Splaiul Tudor Vladimirescu, \\ 300173, Timisoara, Romania
}

\begin{abstract}
Placental blood circulation has certain features that allow the exchange of nutrients between the maternal and fetus blood, respectively allow exchanges of nutrients between the mother and the fetus. We studied 50 human placentas. The method used in the case of our study is a standardized method of the Laboratory of Anatomy and Embryology, Victor Babes University of Medicine and Pharmacy, Timisoara, for over 50 years. The making of corrosion concoction followed the recipe of the laboratory using type AGO II plastic substances, differently coloured and then subjected to the corrosive action of hydrochloric acid. The model of corrosion preparations showed the distributions known as dichotomic and magisterial distribution. The normal development of placenta remains a major factor in the grow th and development of the fetus, and maternalfetal vasculature in the placenta is essential in this regard.
\end{abstract}

Keywords: AGO II plastic substances, uteroplacental circulation, pregnancy-induced hypertension, thrombophilia

The process of formation of the placenta, respectively the formation of complex structural and functional connection between the endometrium which is properly prepared for implantation and the fertilized egg, starts from the time when the egg has completely embedded itself into the endometrium.

In the years that followed, the arguments concerning the pure fetal or maternal-fetal origin continued, as well as the ones on the momentum of the connection between the two systems. The question posed by Ramsey when exactly is established the real uteroplacental circulation or how maternal blood enters the intervillous space, as well as the theories issued by Borell, Panigel or Ramsey, are still debated today [1-2].

Fetal circulation: is provided by the two umbilical arteries, branches of the common iliac arteries and umbilical vein carrying venous blood from the fetus to the placenta. Umbilical arteries penetrate the placenta by the umbilical insertion. Before entering the placenta between the two umbilical arteries there is an anastomosis (Hyrtl) equalizing the pressure between the two arteries. They penetrate the chorionic plate and irrigate half of placental territory. In the chorionic plate, they branch creating villous cytyledons and villous arteries -of the primary, secondary and tertiary order leading to capillary netw orks in the villi. These capillaries are arranged in two networks: a central one and a superficial one forming a perivascular plexus [3].

Venous circulation is represented by a number of branches which converge in a single umbilical vein. The total length of villous capillaries is estimated at some 50 $\mathrm{Km}$. Umbilical venous blood flow is $250 \mathrm{~mL} / \mathrm{min}$. The blood-pressure in the capillaries of the villi is about 10 $\mathrm{mmHg}$, increasing to $30 \mathrm{mmHg}$ [4]. Maternal circulation (uteroplacental) is supplied by the spiral arteries, branches of the uterine artery. The spiral arteries are opened into the basal plate and the blood flows through finer vessels that cross through the chorionic plate to the capillaries in the villi [5].

\section{Experimental part}

Material and methods

The database was gathered using the Microsoft Excel program. In the first part beside the figures obtained from the chirurgical procedure we described and classified our patients / cases using frequency tables. Based on this tables and figures we could build some guideline idea which will get us a better characterisation for this pathology. For the statistical significance we applied a Mann - Whitney test.

\section{Study of the corrosion concoction}

We studied 50 human placentas collected immediately after naturally performed births in the Bega Clinic of Obstetrics and Gynecology, Emergency County Hospital, Timisoara, Romania, from 2012 to 2013; 25 placentas from births that are not associated with maternal pathology and 25 placentas from births that are associated with maternal pathology (pregnancy-induced hypertension, thrombophilia, intrauterine growth restriction).

The method used in the case of our study is a standardized method of the Laboratory of Anatomy and Embryology, Victor Babes University of Medicine and Pharmacy, Timisoara, for over 50 years. The making of corrosion concoction followed the recipe of the laboratory using type AGO II plastic substances, differently coloured and then subjected to the corrosive action of hydrochloric acid. This technique has been published and reported in 
the national and international anatomical press, under the signature of Professor Gheorghe Corondan and Lecturer Leonida Bejan in 1956, and was later improved by Ciobanu (1960), Diaconescu (1962), Radu (1968), Kuhn (1961), Rottenberg (1969). The results of this technique are the corrosion preparates to get a clearer picture of allantochorion vessels from the placenta and the umbilical cord. These preparates provide a 3D image that is very close to real, thus allowing the study of vascular arborisation.

\section{Results and discussions}

All our 50 cases were hospitalised in Bega Clinic. The patients were split in two equal groups: patients with or without maternal pathology ( 25 patients in each group). We grouped the data in frequency tables in order to have a general characterization of the gestational period, the placentas weight in different scenarios (tables 1,2). In order to see if there are statistical differences betw een the gestational periods we applied a Mann - Whitney test. We obtained that there are extremely significant differences $(p<0.001)$ within the two groups, more exactly the patients with maternal pathology are more likely to give birth much sooner. As well we measured the placentas weight in the two groups. After applying the Mann - Whitney test, again we obtained extremely significant differences $(p<0.001)$.

\section{Macroscopic aspects of the placenta}

Regarding the placental weight - shown in table 2 - we obtained a rise that indicated that the placenta weight/ birth weight ratio is $1 / 5$, not $1 / 6$, as it is mentioned in some studies in the literature [6-7]. Therefore, the term placentas present large weight variations. In the third trimester of pregnancy, the placenta grows more than the fetus. The placenta development is directly dependent on blood flow through the umbilical artery [8-10].

There are many factors that can lead to placental hypotrophy, such as: genetic variation, the length of the umbilical cord, preeclampsia, thrombophilia, obesity, maternal hypertension, most fetal malformations, smoking during pregnancy, etc. [11-15]. We found 5 cases of pregnancy-induced hypertension, with placental hypotrophy directly related to fetal hypotrophy.

The examination of the corrosion preparations led to several aspects regarding the distribution of the allantoic vessels:

- Whe did not reveal any anastomosis in placental venous territory (fig 1, fig 2).

- the three types of ramifications existing at the placental level are divided as follows: the first order branches give the second order branches, so that the later branches of the third order penetrate into the corium plate (fig 3, fig 4) Table 1

THE DISTRIBUTION OF GESTATIONAL AGE OF PREGNANCY AND NUMBER OF PLACENTAS IN PREGNANCIES WITH OR WITHOUT BEING ASSOCIATED WITH MATERNAL PATHOLOGY

\begin{tabular}{|l|l|l|l|}
\hline \multirow{2}{*}{ Groups } & $\begin{array}{l}\text { Gestational age } \\
\text { of pregnancy }\end{array}$ & $\begin{array}{c}\text { Number of } \\
\text { placentas }\end{array}$ & $\%$ \\
\hline \multirow{4}{*}{$\begin{array}{l}\text { Group 1 (patients with matemal pathology. } \\
\text { Gestational age and the number of } \\
\text { placentas in high-risk pregnancy) }\end{array}$} & 32 weeks & 1 & $4 \%$ \\
\cline { 2 - 4 } & 33 weeks & 1 & $4 \%$ \\
\cline { 2 - 4 } & 34 weeks & 2 & $8 \%$ \\
\cline { 2 - 4 } & 35 weeks & 2 & $8 \%$ \\
\cline { 2 - 4 } & 36 weeks & 1 & $4 \%$ \\
\cline { 2 - 4 } & 37 weeks & 7 & $28 \%$ \\
\cline { 2 - 4 } & 38 weeks & 11 & $44 \%$ \\
\hline Total group 1 & 25 & $100 \%$ \\
\hline \multirow{2}{*}{$\begin{array}{l}\text { Group 2 pathology) } \\
\text { pathents without matemal }\end{array}$} & 38 weeks & 8 & $32 \%$ \\
\cline { 2 - 4 } & 39 weeks & 13 & $52 \%$ \\
\cline { 2 - 4 } & 40 weeks & 4 & $16 \%$ \\
\hline Total group 2 & 25 & $100 \%$ \\
\hline
\end{tabular}

Table 2

WEIGHT OF STUDIED PLACENTAS CORRELATED WITH GESTATIONAL AGE OF PREGNANCIES WITH OR WITHOUT BEING ASSOCIATED WITH MATERNAL PATHOLOGY

\begin{tabular}{|l|l|l|}
\hline \multicolumn{1}{|c|}{ Groups } & \multicolumn{1}{c|}{$\begin{array}{c}\text { Gestational age of } \\
\text { pregnancy }\end{array}$} & \multicolumn{1}{c|}{$\begin{array}{c}\text { Placental } \\
\text { weight }\end{array}$} \\
\hline \multirow{2}{*}{$\begin{array}{l}\text { Group 1 (patients with matemal pathology. Gestational } \\
\text { age and the number of placentas in high-risk pregnancy) }\end{array}$} & $32-34$ weeks & $310 \mathrm{~g}$ \\
\cline { 2 - 3 } & $34-36$ weeks & $360 \mathrm{~g}$ \\
\cline { 2 - 3 } & $36-38$ weeks & $440 \mathrm{~g}$ \\
\hline Total group 1 & 38 weeks & 25 patients \\
\hline \multirow{2}{*}{ Group 2 (patients without maternal pathology) } & 39 weeks & $510 \mathrm{~g}$ \\
\cline { 2 - 3 } & 40 weeks & $540 \mathrm{~g}$ \\
\hline Total group 2 & 25 patients \\
\hline
\end{tabular}

Fig. 1.Placenta at 38 weeks, with a central insertion of the umbilical cord (fetal face)
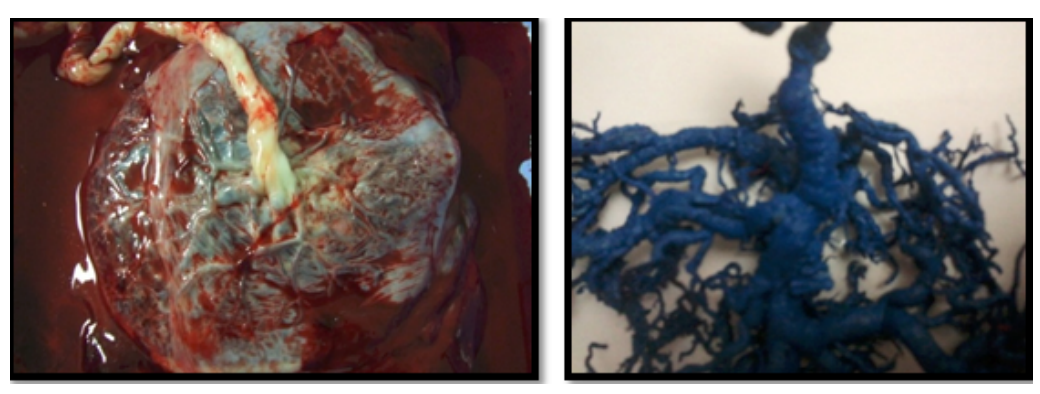

Fig. 2. Placenta - fetal face - corrosive agent 


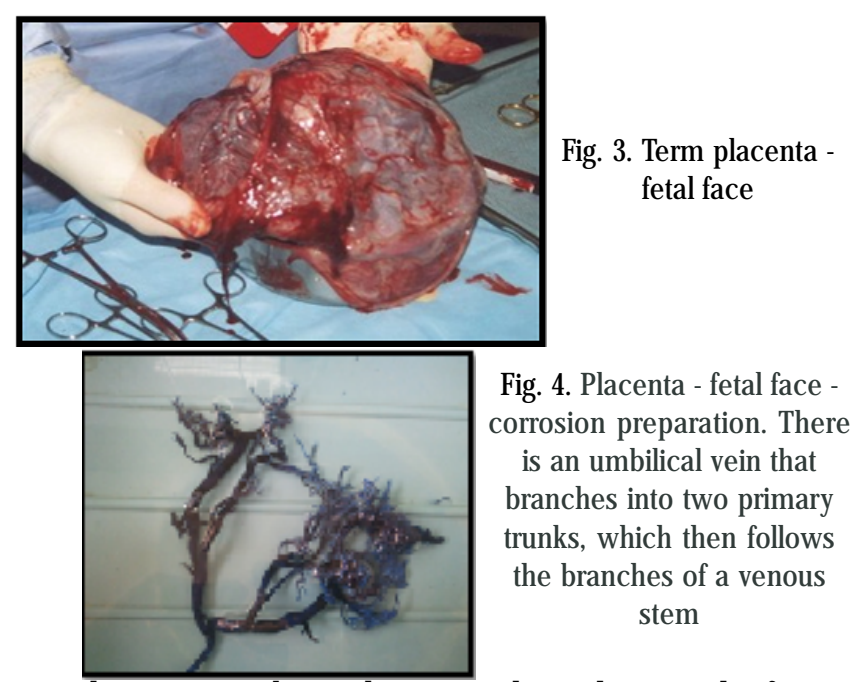

- the venous branches are then disposed after a dichotomic or magistral division pattern (from which branches of much smaller diameter start) (fig 5, fig 6).

- the arterial division differs from the vein;

- in the vast majority of cases, most anastomoses have been encountered at the cord insertion level (in 43 cases out of 50 , which is $86 \%$ ).

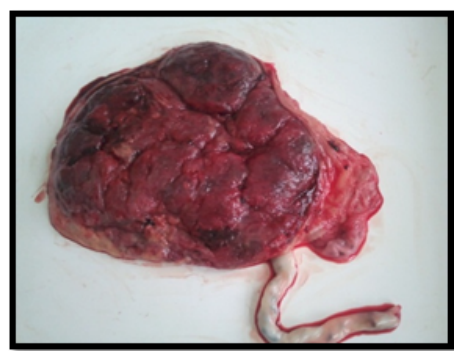

Fig. 5. Placenta at 40 weeks ; the cotyledons are separated by grooves (maternal surface)

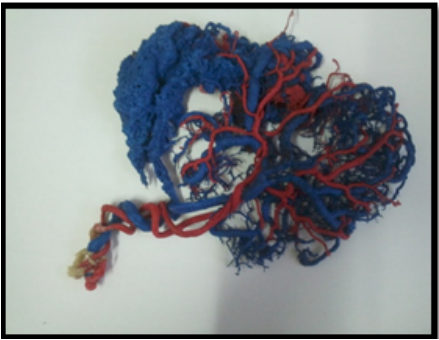

Fig. 6. Term placenta, fetal face - corrosive agent. The umbilical vein branches dichotomously, while the umbilical arteries branch into two trunks of almost equal calibers

\section{Conclusions}

The examination of the placental parameters - shape (the size of placentas clinically examined after birth was variable, the majority having a disc shape) and weight - is important, as a preliminary stage for the study of the placental architecture.

The examination of the placental surfaces provided data on the possible placental pathologies. We have not demonstrated the presence of shape placental abnormalities in our study. Placental angiogenesis has a local component different from angiogenesis found in other anatomical regions. Placental development is a complex process; villosis vascularisation complicates and a dysfunction of this may lead to placental insufficiency.

Placentas that were examined, showed some abnormalities of shape, weight or umbilical cord due to pregnancy-induced hypertension.

Also, we obtained a significant lower weight in the case where we have maternal pathologies present $(p<0.001)$.

\section{References}

1.DE PAULA C.F.S. RUANO R.., CAMPOS J., ZUGAIB M., Quantitative analysis of placental vasculature by threedimensional power Doppler ultrasonography in normal pregnancies from 12 to 40 weeks of gestation. Placenta 2009; 30: 142-148.
2.ANTONIO-GUIMARAES H., DA COSTA L.L., JUNIOR E.A., NARDOZZA LMM, NOWAK PM, MORON AF et all., Angiogenesis and vascular assessment through threedimensional power Doppler ultrasonography. Arch Gynecol Obstet 2008; 277: 195-200.

3.PETRE I., FOLESCU R., BACEAN O., BORDIANU A., LUCA I.M., BERNAD E., CRAINA M.L., The macroscopic examination of the placental vasculature with a corrosive agent, Romanian Journal of Morphology and Embriology, Vol. 55, No.2 Suppl., 2014, pp: 613-617 4.BERNAD, E., PETRE, I., BERNAD, S.I., ILINA, R., -Fetoplacental Network Hemodynamics Investigations, Using Vascular Casting Model, Mat. Plast., 52, no. 4, 2015, p. 582-585

5.IVAN, M.V., PETRE, I., VLAICU, B., APOSTOL, A., TESLOIANU, D., MUNTEANU, M., COSTACHESCU, R., MOLERIU, L.C., LAZAR, F., The Use of Pulse Wave Velocity in Predicting Pre-Eclampsia in High-Risk Women , Rev. Chim. (Bucharest), 69, no. 5, 2018, p. 1260 - 1263 6.BONTE D.C., IORDACHE,O., PETRE I., CRAINA M., CHIRIAC V.D., STOIAN D., MOLERIU L.C., SISU A., Macroscopic Examination of Placental Vascularization with a Corrosive Agent in Pregnant Women Diagnosed with Thrombophilia, Mat. Plast. 54, no. 4, 2017, p. 678-681 7.MOZA A., PETRE I, ILINA R., PANTEA S., The Management of Pregnancy with Vasa Previa, The 13th Conference of the RomanianGerman Society of Obstetrics and Gynecology,Timi-oara, Romania, 14-16 Sept. 2017, pag 189 - 193, Ed. Filodiritto Editore Proceeding,ISBN 978-88-95922-959

8.BERNAD S., MOZA A., PETRE I., BERNAD E., Hemodynamic Evaluation of the Umbilical Cord, The 13th Conference of the Romanian-German Society of Obstetrics and Gynecology,Timisoara, Romania, 14-16 September 2017, pag 49-53, Ed. Filodiritto Editore Proceeding, ISBN 978-88-95922-95-9

9.IVAN M.V., ZALA A., AGOP A., PUIU E., VAIDEANU D., PALAMACIUC I., IANCU D.T, DABIJ A R.C. Several aspects about fractality role in the dynamics of complex systems. ISSN 1223-7027 Revista UPB, vol 79, pp 235-246

10.MOZA A., BRISAN L., BURLICA S., PETRE I., NYIREDI A.,The Management of Pregnancy with Antepartum Fetal Death, The 13th Conference of the Romanian-German Society of Obstetrics and Gynecology,Timiooara, Romania, 14-16 September 2017, pag 515-519, Ed. Filodiritto Editore Proceeding, ISBN 978-88-95922-95-9

11.MITRANOVICI, M.I, PUSCASIU, L., CRAINA, M., IACOB, D., CHIRIAC, V.D., IONITA, I., MOLERIU, R.D., FURAU, GH, SISU, A., PETRE, I.,The Role of Low Molecular Weight Heparin in Pregnancies of Patients with Inherited Thrombophilia that Have Presented (and) Thrombotic Complications During Previous Pregnancies, Rev. Chim. (Bucharest), 68, no. 12, 2017, p. 2970 - 2973

12.MLADIN-MICOARA N.C., LUNGEANU D., MORARIU S.I., CIACLI C.A, MOLERIU L.C., STELEA L., PETRE I., IONITA I., CALAMAR-POPOVICI D., PUSCHITA M., - Biomarkers in Diagnosing Preeclampsia and their Correlation with Blood Pressure, Rev. Chim. (Bucharest), 68, no. 10, p. $2449-2501$

13.TOTH G., PETRE I., CRAINA M., MOLERIU R.D., BOGLUT A., IACOB D., IONITA I., MILOICOV O. BACEAN, Paraclinical Correlations and the Macroscopic Aspect of Placenta in Cases of HTAIS Diagnosis, 5th Congress Of The Romanian Society Of Ultrasound In Obstetrics And Gynecology, Filodiritto Editore Proceeding, Targu Mures, Romania, 20-22 April 2017, pg 482 - 486, ISBN 978-88-95922-88-1

14.UTA M., PETRE I., CRAINA M., CHIRIAC V.D., STELEA L., MOLERIU L.C, POP E., IURCIUC M., STOIAN D., IVAN M.V.- Correlation Between Obesity and Preeclampsia -Risk Factor for Pregnancy, The 17 National Congress of the Romanian Society of Obstetrics and Gynecology, 2022 September 2018, lasi, Romania, pag 833-836, Ed. Filodiritto Editore Proceedings, ISBN 978-88-85813-33-5

15.PETRE I., CRAINA M., CHIRIAC V.D., STELEA L., MOLERIU L.C., POPE., IURCIUC M., STOIAN D., IVAN M.V. - Evaluation of Hemodynamic and Arterial Stifness Parameters in Women with Htais/Preeclampsia, The 17thNational Congress of the Romanian Society of Obstetrics and Gynecology, 20-22 September 2018, lasi, Romania, pag 639-643, Ed. Filodiritto Editore Proceedings, ISBN 978-88-85813-33-5

$\overline{\text { Manuscript received: } 17.12 .2018}$ 